S'rokes, W. E. and F. H. Hull: Peanut breeding. Journ. Amer. Soc. Agron. 22 (1930), $1004-1019$.

Strauss, J. L. and A. L. Gruzzard : The effect of calcium, magnesium and potassium on peanut yields. Soil Sci. Soc. of America, Proceedings 1947, 12 (1948), 348-352.

Thornton, G. D. and F. E. Broadbent : Preliminary greenhouse studies of the influence of nitrogen fertilization of peanuts on nodulation, yield and gynophore absorption of this element. Journ. Amer. Soc. Agron. 40 (1948), 64-69.

Wiersum, L. K. : Watertransport in the xylemas related to calcium uptake by groundnuts (Arachis hypogaea L.). Plant and Soil 3 (1951), 160-169.

WolK, P. C. VAN DER: Researches concerning geocarpy. Publications sur la physiologie végétale. Nimègue, 1914.

Erratum to

\title{
INFLUENCE OF TILTH ON SOIL AND AIR-TEMPERATURE
}

\author{
R. H. A. VAN DUIN \\ Laboratory for Physics and Meteorology, Agrilcultural University, \\ The Netherlands
}

In the arcticle mentioned in the title (Neth. J. Agr. Sci. 2, 1954, 4 : 229-241) the phase shift between the heatflux into a layered soil and the temperature wave at the surface must read:

$$
-\varphi=\operatorname{arctg} \frac{\frac{Q_{s}}{Q_{a}} \sin \left(\frac{\pi}{4}-\Delta \varphi_{0}\right)+\sin (\operatorname{arctg} 1 / 2 j)}{\frac{Q_{s}}{Q_{G}} \cos \left(\frac{\pi}{4}-\Delta \varphi_{0}\right)+\cos (\operatorname{arctg} 1 / 2 j)}
$$

where $Q_{s} Q_{a}$ is given by eq. $13 a$.

The results of the calculations in the case of a dry soil with $q_{\mathrm{s}}+q_{\mathrm{a}}=$ constant are decreased by about $3 \%$ if eq. $17 \mathrm{a}$ is used. Owing to this correction the corresponding part of table 3 must be replaced by:

\begin{tabular}{|c|c|c|c|c|c|c|c|c|}
\hline & \multicolumn{4}{|c|}{$\mathrm{z}=0$} & \multicolumn{4}{|c|}{$\mathrm{z}=+5 \mathrm{~cm}$} \\
\hline & $I_{i}$ & $I_{d}$ & II & $\mathrm{II}_{\mathrm{d}}$ & I: & $I_{d}$ & $\mathrm{II}_{\mathrm{c}}$ & $\mathrm{II}_{\mathrm{d}}$ \\
\hline$\stackrel{\mathbf{A}}{\mathbf{T}_{\min }}$ & $\begin{array}{r}18.3 \\
-\quad 4.3\end{array}$ & $\begin{array}{r}21.6 \\
-\quad 7.6\end{array}$ & $\begin{array}{r}27.8 \\
(-13.8)\end{array}$ & $\begin{array}{r}32.8 \\
(-18.8)\end{array}$ & $\begin{array}{r}14.6 \\
-0.6\end{array}$ & $\begin{array}{c}17.3 \\
(-3.3)\end{array}$ & $\begin{array}{c}22.2 \\
(-8.2)\end{array}$ & $\begin{array}{c}26.2 \\
(-12.2)\end{array}$ \\
\hline
\end{tabular}

